\title{
What does materiality mean to integrated reporting preparers? An empirical exploration
}

\begin{abstract}
Purpose-This paper seeks to understand how the principle of materiality gets implemented in integrated reporting contexts.

Design/methodology/approach-Drawing on an interpretation of materiality as a social construction, this research explores the meaning that practitioners attach to the principle during their implementation of it. Following an existing framework for exploring materiality in corporate reporting, this study investigates the meaning by focusing on who participates in determining integrated reporting materiality and to whom the integrated report (IR) is addressed. This analysis benefits from in-depth interviews with persons involved in the preparation of IR for a firm that pioneered this form of reporting.

Findings-In IR preparers' view, the meaning of materiality corresponds with the company strategy: The IR describes strategic priorities and related actions and results. Capital providers are the primary intended addressees of the material information. Although several actors engage in IR preparation, the materiality determination process is governed by a specific "IR hub" in strict collaboration with and dependence on the CFO.
\end{abstract}

Research limitations/implications-In an IR context, materiality is intimately connected to the function that preparers assign to the report.

Originality/value-This novel research opens the "black box" of the process by which materiality gets defined and then practically implemented in an IR context.

Keywords: materiality; integrated report; strategy; reporting process; reporting preparers.

Article classification: Research paper.

\section{Introduction}

Materiality is a multifaceted concept that permeates the entire field of accounting; it generally refers to the need to provide relevant information to users of corporate reporting (Bernstein, 1967). Previous research offers a variety of definitions of the principle of materiality (Brennan and Gray, 2005; Messier et al., 2005), which shift over time (Edgley, 2014) and across various corporate reporting contexts (e.g. financial vs. non-financial) (Eccles and Krzus, 2014). The presence of these multiple definitions reflects materiality's "malleable nature" (Edgley, 2014, p. 255), such that the way the principle ultimately is implemented cannot be defined ex ante. As highlighted in both academic and professional literature, the practical implementation of materiality principles entails a process in which the report preparers mobilize their expertise and apply their judgments to distinguish between 
useful information that must be disclosed and irrelevant, insignificant information (Bernstein, 1967; Dohr, 1950; Reninga, 1968).

Although the implementation of materiality is demanding even in a traditional corporate financial reporting context, judgements appear even more critical in non-financial reporting settings (e.g. sustainability), in which the amount of discretion is greater, due to the lack of detailed guidance and the shortage of actual implementation experience (Guthrie and Parker, 1990). For example, in the integrated reporting (IR) context, the guidance offered by the International Integrated Reporting Council (IIRC) is based in principle, such that it allows for significant variation in the way companies may apply the materiality principle and develop their "materiality determination process" (IIRC, 2013). Furthermore, IR is an emerging practice, marked by uncertainty about whether and how it will become institutionalized (Rowbottom and Locke, 2016; Humphrey et al., 2017). In turn, the IIRC, accounting professionals, and standard setters have highlighted challenges associated with implementing materiality in an IR context (e.g. AICPA and IIRC, 2013; EY, 2013; IIRC, 2015; CDP et al., 2016; IAAER et al., 2016). As addressed in more detail in Section 2, these challenges include aligning the company's materiality process with regulatory frameworks, offering a concise explanation of the business models of companies in complex industries, and providing a balanced view of the issues that appear to be material to both the company and external stakeholders.

As such, the IR context represents an ideal setting in which to explore how preparers engage practically in the process of determining what is material and what is not. A few studies empirically investigate the materiality process in an IR context (Higgins et al., 2014; Stubb and Higgings, 2014) and reveal that materiality judgements strongly orient IR preparation. In this respect, and in response to recent calls for more case research on integrated reporting practices (De Villiers et al., 2014 and 2015), exploring the practical implementation of materiality may offer greater understanding of IR practices, especially in reference to who are involved in IR preparation (and who thus define and implement materiality) and how they work and interact to decide to whom the report will be addressed.

To address these questions, this current qualitative analysis centres on the IR preparation process of Assicurazioni Generali, an "IR pioneer" that joined the IIRC pilot program in 2012 and actively participates in three IIRC business networks (international business network, insurance international network and national network of Italian IR adopters). Assicurazioni Generali-which is among the biggest insurance groups in the world and the leader in Italy-has published four annual IRs (2013, 2014, 2015 and 2016), in accordance with International Integrated Reporting Framework (IIRF) principles issued by the IIRC (IIRC, 2013). The current analysis relies on in-depth interviews with managers and employees involved in preparing its IRs.

The theoretical background for this research stems from an interpretation of materiality as a social construction, as derived from work by the philosopher John R. Searle to describe the "construction" of social institutions (Searle, 1995). With regard to how organizations apply materiality 
during their IR preparation, this conceptualization should be particularly meaningful for developing critiques about how companies adopt the IIRC's materiality guidelines. Also in line with Searle's theory of institutional reality, Eccles and Krzus (2014) propose a framework for analysing materiality with reference to who defines materiality and to whom the report is addressed. The current study adopts this framework.

This article proceeds as follows: Section 2 contains a review of extant accounting research related to materiality, citing the various reporting contexts in which the issue has been addressed (i.e. financial, non-financial, integrated). ${ }^{1}$ Section 3 provides the theoretical background on which this research is based; it shows how materiality can be interpreted meaningfully as a social construction. Section 4 details the company, Section 5 describes the methodology, and Section 6 provides empirical evidence about how materiality is interpreted and implemented in the company. Finally, Section 7 outlines the results according to the focal theoretical lens, and Section 8 concludes by highlighting the contributions and limitations of this study.

\section{Concept of materiality in corporate reporting}

The origins of the materiality concept are obscure (Hicks, 1964; Holmes, 1972), though it is well accepted that the concept first appeared in the context of financial reporting, where a general consensus holds that information is material if it influences the decisions of (reasonable) users. For example, the American Accounting Association suggests "[a]n item should be regarded as material if there is reason to believe that knowledge of it would influence the decisions of an informed investors" (AAA, 1957, p. 8). Despite this general consensus, debate continues about how materiality should be implemented, that is, the process for determining what information is material for users. Although published a half-century ago, Bernstein's words still resonate: "The concept of materiality, when generally expressed, is simple to understand. However, when it is made a central concept in the application of accounting principles, a lack of specific definition converts it into a prime problem area" (Bernstein, 1967, p. 88). Materiality assessments often focus on reporting misstatements (e.g. omissions, errors in estimations), such that many studies and standard setters recommend using thresholds to define the relevance of such misstatements (e.g. AASB, 2009; ESMA, 2011; Mio and Fasan, 2013; Lydenberg, 2012; Tuttle et al., 2002), in which case the magnitude of misstatements becomes the guide for implementing materiality. Other scholars (e.g. Eccles et al., 2012) argue that the nature of misstatements also needs to be addressed. Commenting on the International Financial Reporting Standard (IFRS) framework, Deloitte (2010) argues that materiality is an entity-specific form of relevance, based on both the magnitude and the nature of the items to which the information relates. The concurrent consideration of quantitative and qualitative issues makes the materiality

\footnotetext{
${ }^{1}$ Unlike interpretative studies that explore auditing issues related to materiality (e.g. Carpenter et al., 1994; Edgley, 2014), the present paper deliberately omits such issues and focuses on the preparation of corporate reports.
} 
determination process difficult, such that it likely demands professional judgements (Bernstein, 1967).

In the context of non-financial reporting, materiality appears even more difficult to apply than in financial settings (Guthrie and Parker, 1990). Non-financial information seeks to capture a broader concept of value creation, and even if the impact of an event might be quantified, it is not possible to establish a unique threshold, because the event may affect more than one form of capital (e.g. financial and non-financial). Yet non-financial information sometimes is not quantifiable, and it might affect long-term value creation but not by influencing the items specifically identified for use as the threshold (Mio, 2013). In the Global Reporting Initiative (GRI) guidelines, materiality reflects an organization's significant economic, environmental and social impacts, together with their influence on stakeholders' assessments and decisions. In this respect, the guidelines embrace a concept of materiality based on thresholds, parallel to the interpretation in financial reporting context. However, as acknowledged by that same institution (GRI, 2013), the concept of materiality for sustainability reporting is more complex, because it is "concerned with a wider range of impacts and stakeholders." A "materiality matrix" tool attempts to include the company's and its stakeholders' perspectives on what is material; for example, the process-oriented AA1000 framework developed by AccountAbility (an international institute dedicated to promoting social, ethical and overall organizational accountability) offers a five-step test to determine what is material and what is not, which seemingly should result "in a comprehensive and balanced understanding and prioritisation of its material sustainability issues" (AccountAbility, 2008, p. 13). In this respect, the process for determining materiality constitutes a "strategic business tool" that companies can adopt to "apply a sustainability lens to business risk, opportunity, trendspotting and enterprise risk management processes" (KPMG, 2014 , p. 3). However, considering the complexity associated with addressing materiality for nonfinancial reporting, some scholars (e.g. Eccles et al., 2012) call for more sector-specific guidelines about which sustainability issues are most material to each sector and which key performance indicators (KPIs) provide substantial disclosure of ESG performance. The U.S. Sustainability Accounting Standards Board (SASB) guidelines are the most recent representation of such an approach (SASB, 2016). Thus, in non-financial reporting contexts, materiality assessments involve not reporting misstatements (as in financial reporting contexts) but rather selecting which issues have the strongest sustainability impacts (CDP et al., 2013).

The emergence of integrated reporting as a new practice (Busco et al., 2013; De Villiers et al., 2014; Atkins et al., 2015; Rowbottom and Locke, 2016) also suggests the need to investigate how its major proponent-namely, the International Integrated Reporting Council (IIRC)—defines materiality and recommends its practical implementation (IIRC, 2013, 2015). Although materiality represents a "starting point" for the IR preparation process (PwC, 2015, p. 10), various challenges surround the application of this principle (AICPA and IIRC, 2013; EY, 2013). The IIRC does not offer a strict definition of materiality but instead suggests that "[i]n Integrated Reporting, a matter is 
material if it could substantively affect the organization's ability to create value in the short, medium or long term," so what materiality is actually "varies across report forms due to differences in audience, purpose and scope" (IIRC, 2015, p. 4). Understanding the perspectives of key stakeholders thus is critical for identifying relevant matters, but applied judgements also are needed to determine which information to disclose about material matters. This process entails "consideration from different perspectives, both internal and external," and "regular engagement with providers of financial capital and others" (IIRC, 2015, § 3.29).

The implementation of the principle also depends on the materiality determination process, which is "entity specific and based on industry and other factors, as well as multi-stakeholder perspectives" (ibidem). Report preparers receive lists of recommendations for identifying relevant matters, evaluating the importance of relevant matters, developing content and deciding on the depth and frequency of materiality assessments (IIRC, 2015, p. 5). In brief, similar to non-financial reporting, these materiality assessments do not seek to report misstatements but instead attempt to select which issues to include in the report. However, in an IR context, these inclusion decisions reflect the impact of the relevant issues on "the organization's ability to create value in the short, medium or long term" (IIRC, 2015, p. 4). The materiality determination process becomes even more subjective than the process that marks the non-financial reporting context, in that the "value-creation process" is a more vague concept than "sustainability impacts" (CDP et al., 2016).

Previous IR insights highlight the great subjectivity evoked by the concept of materiality in IR (IAAER et al., 2016). In particular, AICPA and IIRC (2013), EY (2013) and KPMG (2014) elucidate additional challenges associated with its implementation. Difficulties may arise from attempting to align the company's materiality process with regulatory frameworks (e.g. IFRS) or explaining the business model concisely, particularly when the company operates in complex industries. Furthermore, it becomes challenging to establish a balanced view of the issues that are material to both the company and its external stakeholders, and there may be concerns of a potential loss of competitive advantage if sensitive information were disclosed.

Despite the importance that the IIRC and other standard setters and professionals attribute to the principle of materiality in the process of IR construction (e.g. AICPA and IIRC, 2013; EY, 2013; IIRC, 2015; CDP et al., 2016; IAAER et al., 2016), academic debates about how materiality gets determined and implemented in IR contexts have remained largely conceptual. Previous studies focused on materiality predominantly explore the determinants of any disclosures provided about the materiality determination process. For example, some firm-level characteristics strongly orient the disclosure achieved through this process (Fasan and Mio, 2016), similarly to what already demonstrated with reference to the specific IIRC content elements (e.g. Melloni et al., 2016; Stacchezzini et al., 2016). However, no previous academic studies explore the materiality process from a practical perspective, even though de Villiers et al. (2014) identify materiality as a central topic for a future research agenda, and Unerman and Zappettini (2014) highlight the possibility that 
companies use materiality to exclude negative information and rhetorically report an image of sustainability that differs from their underlying behaviour. This finding contradicts the IIRC requirement (IIRC, 2015, § 3.19) that the materiality process should be applied "to both positive and negative matters, including risks and opportunities and favourable and unfavourable performance or prospects. It also applies to both financial and other information." Materiality also may enable companies to set up different discourses to conform "to a new global reporting framework that is standards based, transparent, and comparable with others" (Higgings et al., 2014, p. 1107). In their investigation of the internal mechanisms mobilised by Australian early adopters of IR, Stubb and Higgings (2014, p. 1083) reveal that these companies are changing the materiality process by focusing on "fewer, more strategic issues rather than lots of issues that are, for example, covered by the GRI."

Despite these arguments though, there is a continuing shortage of IR research aimed at opening the "black box" of the process by which materiality gets defined and implemented in practice. The present paper aims to fill this gap, in response to the exhortation to "continue to discuss, dissect, deplore and generally 'look before and after and pine for what is not' in this matter of materiality" (Holmes, 1972, p. 44).

\section{Materiality as a social construction: theoretical frame}

\subsection{Searle's theory of institutional reality}

The idea that accounting is a "social construction" is well developed in accounting research that adopts a critical/interpretative stance (Hines, 1988; Beattie, 2014; Boele and Kemp, 2005; Eccles and Krzus, 2014; Eccles and Youmans, 2016). Starting from this idea, various accounting scholars have elucidated ontological and epistemological perspectives that might be adopted to interpret accounting reality (e.g. Morgan, 1988; Mouck, 2004; Mattessich, 2009; Lee, 2006 and 2009; Barker and Schulte, 2017). In analysing the potential of these perspectives, such scholars acknowledge the general failure to address related, practical issues. For example, Mouck (2004) demonstrates that financial accounting representations often are characterized as epistemologically objective facts, despite their ontologically subjective mode of existence. Lee (2009) criticizes standard setters (i.e. FASB and IASB) for neglecting both ontological and epistemological dimensions of accounting representations, and Barker and Schulte (2017) reject the fair value measurements (FVM) in IFRS, noting that fair value is unknowable for some assets. ${ }^{2}$

These studies mainly draw on the theory of institutional reality proposed by John R. Searle (Searle, 1995, 2010), who notes that social institutions, unlike "brute" facts (i.e. physical or chemical events that exist irrespective of human preferences, evaluations or moral attitudes), exist and

\footnotetext{
2 Specifically, Barker and Schulte argue that the new IFRS pertaining to FVM neglects the "ontological variation" of fair market values, though "there is epistemological objectivity [...] in the wording of the accounting standards themselves" ( $p$. 66), so determining accounting representations is in direct contradiction with market participants' perspective, which is what the IFRS solicits.
} 
influence the social world only to the degree that their meaning is shared across their "audience," such that they "are things that exist only because we believe them to exist" (Searle, 1995, p. 1). In his ontological investigation of how social facts exist, Searle argues that three elements are necessary to account for devising a social reality: assignment of function, collective intentionality and constitutive rules.

First, social institutions are socially constructed by humans who assign them a function. They are built to serve this function, and they only "exist relative to the intentionality of observers, users, etc." (Searle, 1995, p. 9). Paraphrasing Searle (1995, p. 23), materiality participates to the constitution of social world to the extent to that it "symbolize[s], represent[s], stand[s] for, or - in general - to mean something or other." It then follows that the materiality principle exists only to the extent of the meaning attached to it. A definition cannot cause materiality to affect social life; such an impact requires the assignment of meaning, even beyond its formal definition. In implementing the focal principle, report preparers must project a meaning onto the principle, and then by sharing this meaning, they can construct it socially.

Second, the implementation of the principle requires people to work together to assign the meaning that constitutes its function, which implies the need for collective intentionality. An intentional state can be shared with the related states of other members of the group, which indicates a precondition of cooperative behaviour. As explained by Barker and Schultze (2017, p. 58), "what the collective is trying to do is a question of ... social outcome that the collective is seeking to bring about."

Third, because of the immaterial nature of concepts (Searle, 1995; Kallinikos, 2012), their function is never an intrinsic property of the concepts themselves. They deserve constitutive rules exerted through "status function declarations," such that "[A]ll human institutional reality is created and maintained in existence by status function declarations" (Searle, 2010, p. 13). A concept serves a function to the extent to that the collective declares and accepts this function.

Although the materiality principle has been interpreted as a social construction in accounting research (Carpenter et al., 1994), ${ }^{3}$ no previous studies draw on Searle's concepts to explore how the materiality principle might be implemented in the process of IR preparation.

\subsection{Eccles and Krzus's framework for analysing IR materiality}

The application of Searle's theory of institutional reality (Searle, 1995; 2010) to study the implementation of the materiality principle in an IR context also requires investigating how preparers collectively come to share a meaning and implement this principle. The existence of multiple definitions, along with a lack of detailed guidance, makes materiality "malleable" (Edgley, 2014, p. 255). How the principle is implemented in practice cannot be defined ex ante. Rather than struggling

\footnotetext{
${ }^{3}$ In their study of the relationships between materiality judgements and audit firm culture, Carpenter et al. (1994) show that materiality is a social behavioural phenomenon that relies on the social interaction among practitioners involved in implementing the principle. However, they do not apply Searle's theory of institutional reality.
} 
to produce an ultimate definition of materiality then, perhaps the goal should be to determine how preparers exercise their judgment to determine what is material, on a case-by-case basis (Eccles and Krzus, 2014).

Corporate practitioners already are involved in this materiality determination process, such as chief financial officers (CFOs), IR managers and staff and members of the sustainability or financial reporting departments (Eccles and Krzus, 2014). Senior managers and those involved in corporate governance also primarily assign meaning to the materiality principle, and the board of directors ultimately has the responsibility for making this determination (Eccles and Youmans, 2016). Various stakeholders may be consulted and participate in the process of defining what topics are material for IR; the company, together with its board of directors, "makes the ultimate decision as to what is material ... it exercises judgement as to what is both important and relevant to the user audience, and of equally symbolic importance, what is not relevant or important enough to report" (Eccles and Krzus, 2014, p. 128). That is, a company forms its own view of what is material for its stakeholders, even though each stakeholder may have a different understanding of what is material and what is not. The company socially constructs a sense of what it thinks its stakeholders' view is. The company's IR preparers-herein, organizational members involved in deciding the content and effectively drafting the IR - thus collectively come to attach a meaning to materiality that reflects and serves to implement their idea of what IR is and who the (most important) addressees are (Eccles and Youmans, 2016).

The social construction of this materiality therefore relies on both who, within the company, actively participates in constructing the meaning of materiality, as well as to whom this information is addressed. The relevance of these actors confirms accounting's "ontologically subjective mode of existence" (Barker and Schulte, 2017, p. 58) and suggests the need to investigate the epistemological dimension of the meaning of materiality-that is, the process through which this meaning gets collectively shaped. According to Eccles and Krzus's (2014, p. 121) framework for analysing IR materiality, two key questions should be directed to integrated reporters, to detect their social construction of materiality:

- Who participates in the materiality determination process?

- Whom do the institution's agents plan to address when they determine which issues are material and which issues are not?

\section{The company and its IR}

The current empirical analysis of the meaning of materiality in an IR context is based on a qualitative analysis of Assicurazioni Generali (hereafter, Generali or the company), one of the biggest insurance groups in the world and the top firm in Italy. Generali is headquartered in Trieste, but as a multinational group, it is present in more than 60 countries, encompassing a history of more than 200 years, 430 companies, 500 billion euro in assets and nearly 76,000 employees. Its business 
activities include life (savings, family protection, unit-linked policies) and property and casualty (car, home, accident, health) insurance products. Its engagement in IR started in 2012, when it joined the three-year IIRC pilot programme launched in September 2011. Its first IR was dated 2013; since then, Generali has published four IRs (2013, 2014, 2015 and 2016). It also has expressed its commitment to implementing integrated thinking and reporting, embracing several IIRC initiatives aimed at sharing best practices and experiences with IR (e.g. IIRC Business Network, IIRC Insurance Network, national Italian network).

Since its first IR, Generali has integrated IR information in the management report section of its annual financial report. The IR thus includes sections that comply with (mandatory) financial reporting regulations (e.g. consolidated financial statements, notes), as well as sections that provide additional (voluntary) information, in line with IIRF requirements (e.g. "Our group," "Outlook"). The details on the implementation of the IIRC materiality guiding principle appear in the "Notes to the management report." Generali's approach can be summarized as follows: "In accordance with the materiality principle, the report should only disclose information to explain to providers of financial capital how an organization creates value over time" (IR 2013, IR 2014). However, the company also recognizes that matters that significantly affect its ability to create value over time are connected to different stakeholder categories, such that "value is created by focusing on the following primary stakeholders: the financial community, its people, clients, sales force and regulators" (IR 2014; see also IR 2013 with slightly different wording). It further specifies that "in order to identify material matters, Generali relied on strategic management control tools, such as the strategic plan and the Quarterly Business Review."

\section{Method}

The data for the analysis mainly were collected through interviews with IR preparers. The authors conducted 14 in-depth, semi-structured interviews with Generali top managers, middle managers and staff members. As Table 1 details, the interviews included all members of the IR hub, the general managers and group CFO, a foreign subsidiary CFO, the group investor relator and the group communication manager - that is, the key actors involved in the process of IR drafting, approval and communication. By interviewing some IR hub members two or three times, different but complementary aspects of how the principle of materiality gets implemented in the context of the IR could emerge, as detailed next.

All the interviews took place between September 2015 and January 2017, and they either were taped or summarized in detailed notes, depending on the interviewee's preference. The meetings took place at the company's headquarters or the authors' university; some interviews were conducted by phone. The authors also observed these participants during IR presentations to various panels (e.g. IIRC insurance network meetings, university lecture, public events) and interviewed them before or after these events. All the interviewees were previously informed about 
the general aim of the research and ensured that their privacy and anonymity would be carefully protected.

\begin{tabular}{lll}
\hline Informant & Duration (minutes) & Number of Interviews \\
Head of the IR hub & 806070 & 3 \\
Head of the group IR framework & 404060 & 3 \\
IR staff 1 & 7540 & 2 \\
IR staff 2 & 6540 & 2 \\
General manager and group CFO & 90 & 1 \\
Foreign subsidiary CFO & 50 & 1 \\
Group investor relator & 40 & 1 \\
Group communication manager & 40 & 1 \\
\hline
\end{tabular}

Table 1. Informants, duration and number of interviews

The interviews sought a clearer understanding of how the principle of materiality is implemented in an IR context. Drawing on previous studies (Eccles and Krzus, 2014), the initial questions asked about who in the company actively participates in identifying material issues and to whom the material information is addressed. More direct questions also covered how they interpret materiality and how this interpretation has evolved over time (see Table 2 for some example questions).

- What is your role in company? How long have you covered your current position?

- Who is the primary audience of the IR?

- Do you follow the IIRC framework when preparing the IR?

- Who participates in the process of IR preparation?

- How do you participate in the process of IR preparation?

- Who participates in the materiality determination process?

- How do you participate in the materiality determination process?

- Whom does the company address when it determines which issues are material?

- Has the materiality determination process changed over time?

- What does materiality mean in the IR context?

- Has the meaning of materiality changed over time?

Table 2. Examples of questions asked during the interviews

For the content analysis of the interviews, transcribed in their original language (English or Italian), the coding categories were generated on the basis of the Eccles and Krzus's theoretical framework and then discussed among the authors, as suggested by previous studies (Strauss and Corbin, 1990). One category served to capture who is involved in the materiality determination process, while a second category was used to detect to whom the material issues were addressed. In each of the two categories, we distinguished further among different actors: members of the IR hub, employees, the board of directors, the strategy office, customers, the CFO, the CEO, 
debtholders, shareholders and financial analysts. A third category captures specifically the quotes about the meaning assigned to materiality by Generalis staff. We used this category when interviewees unveil their interpretation of the materiality principle, what is the function of materiality in the construction, and examples of the practical implementation of this principle. In addition, we embedded in this category details of how Generali's staff discussed and shared the meaning assigned to the materiality principle across the company. Finally we also coded quote that refer to the relationship between the materiality principle and other IIRC guiding principles underpinning the preparation of the IR. Each interview was coded by all three authors, who then discussed the results of the coding; no substantial differences arose in this process.

\section{Findings}

\subsection{Who participates in the materiality determination process?}

The process of IR preparation is managed by the so-called Group Integrated Reporting \& CFO Hub (hereafter, the IR hub or IR team). This team comprises four members: IR manager (i.e. head of the IR hub), IR middle manager (i.e. head of the Group IR framework) and two IR staff members, one of whom is also part of Group Social Responsibility team (IR staff 1) and another who works exclusively for the IR hub (IR staff 2). The head of the IR hub reports directly to the group CFO.

The IR preparation process benefits from work done from those in charge of defining the strategy. According to the head of the Group IR framework, the strategy team works closely with top management to define new strategies, such that the strategic priorities are set by top management, in collaboration with managers working at different levels, including the chief marketing and chief insurance officers. The strategic priorities identified then are summarised in a PowerPoint presentation that "represents an actual report as there are more than 400 slides" (IR staff 2) and that sheds light on strategic priorities and all the actions that should be implemented by the group and the business units to achieve them, such that "the chairman of the Group is very clear on this aspect: what we need to do is to implement the strategy and nothing else" (head of the Group IR framework).

The official communication of the group's strategy takes place during Investor Day. Although many contacts take place between the IR hub and the strategy team before this date, the IR hub waits for this particular day to learn what can be published in the IR. The actions identified during this formal presentation are those that the IR hub reports. Furthermore, the themes of the strategic plan announced at Investor Day reflect the identification of which lines of action the group plans to pursue. These lines of action also get reported in the IR. That is, the strategic priorities already have been defined by the strategy team, and the IR hub's role is to report on them: "We are the last part of the process. This is the best thing because we do not have to invent things to write into the report! It is exactly the opposite: the management has defined the strategic pillars, then we have to report on them" (head of the Group IR framework). 
In accordance with the Investor Day presentation, the IR hub contacts different offices that contribute to the definition of strategic priorities, asking for additional information. It then prepares a first draft of the report and shares it with the CFO, asking for feedback and further directions. This discussion determines the selection of what to include or not, though the first draft does not include the numbers that ultimately will be in the financial statements, such that "it is disconnected from the specific annual performance in terms of premiums, revenues, operating income, net income as we usually prepare it later (before Christmas)" (head of the Group IR framework).

Once the CFO has approved this report, a second draft goes to the CEO and president, who may provide further feedback. During its meeting with the CFO, CEO and president, the IR hub outlines the contents of report and whether any additional information might be necessary. The goal is to attain "calibration of the message embedded in the document" and "an activity of refinement, consisting of removing the emphasis on some initiatives and adding more focus on others" (head of the Group IR framework). This discussion may prompt significant changes in the content of the report. For example, the head of the Group IR framework reports that in 2015 the president suggested a stronger emphasis on innovation activity, so the document was revised to incorporate this feedback. Finally, the IR is ready to go for board approval, once the financial statements are available and can be included.

Following the publication of the report, the IR is shared internally, and the IR hub starts internal feedback collection. In 2015, the report was submitted to group employees as well as employees of two operating companies, one in France and one in Italy. It organized workshops and work groups, involving more than 100-150 people, in an attempt at obtain suggestions about what should be included in the IR, according to the employees.

Additional inputs come from external stakeholders, such that "The first feedbacks are asked of the investors" (IR staff 2). Insights gained during external presentations (e.g. conferences, seminars) also might be implemented, such as when a student participant in a seminar delivered at an Italian university commented about the lack of information about the history of the group, leading to the addition of a new paragraph ("Our history") to the subsequent IR (i.e. IR 2015).

Regarding the evolution of the process over time, the selection of what should be included in the IR has become less prominent. Compared with the first IRs, the current IR (2016) asserts that no material was produced anew, in that it used only material provided by other offices. In contrast, in 2014, the selection activity was far more prominent, in the effort to decide what to put in the IR, whereas "this year a good job has been done by the strategic office as we have found the information needed almost ready" (IR staff 1). The IR hub therefore focuses more on converting the PowerPoint presentation into text. As the head of the Group IR framework reports, the IR content was selected by the strategic team, but the IR hub presents the PowerPoint content in narrative and graphic form, so it required some additional information from the strategic team. 
Furthermore, the IR hub activity is progressively benefiting more from the work done by other offices, possibly in light of the greater awareness overall of what IR is and what information is needed to draft the report, such that in "the Integrated Thinking and Reporting process we are just the final piece in the report preparation" (IR staff 1). Members of the IR hub thus note that they are more concerned about stimulating internal offices that perceive distance among themselves to work together in support of the IR preparation.

\subsection{Whom do the institution's agents address when they determine which issues are material?}

According to Generali, the IR is an instrument primarily directed toward external users, to improve communication with external stakeholders and meet the information needs of capital providers. It is thus not surprising that "the main sponsor of IR is the Investor Relator" (Group CFO and General Manager). According to this actor, investors are the primary users of IR, because they look for information to understand if they should invest or not in our company."

Yet among capital providers, different categories exist, and they develop distinct expectations and information needs. Debtholders seem to be the most interested recipients of the IR (Group CFO and General Manager), and compared with shareholders, they are more interested in corporate strategy and particularly any actions that may risk losses. Debtholders thus tend to use the information provided in the financial statements, such that "they read the annual report from $A$ to $Z$ and ask specific questions on it.... I remember that one day, a particular debtholder approached me with the IR completely underlined" (Group CFO and General Manager). Shareholders and financial analysts also use the IR though. The foreign subsidiary's CFO claims that "financial analysts do not limit their analysis to the numbers presented in the financial statements, but seek further information from the management related to those numbers." Additional users from the financial community include rating agencies and regulators (e.g. Solvency II Supervising Authority). Finally, Generali considers customers and suppliers potential users of the IR, but it also mentions journalists, noting that "with the IR it is easier to explain what we are doing in the short, medium and long run and in strategic terms" (Group Communication Manager).

Generali asserts that this focus on external stakeholders does not preclude the appeal of the IR for internal stakeholders. Even if capital providers are the primary audience, the IR aims to communicate with current and potential employees too. With reference to potential employees as an IR audience, the Group Communication Manager asserts that young university students looking for information about the company should be interested in its IR, because by reading it, "you may gain a complete idea of the company and in a short time."

\subsection{The meaning of materiality in the IR context}

Drawing on Eccles and Krzus's (2014) framework for analysing IR materiality, based on "who" and "to whom" questions, this section outlines some inferences about what materiality means to IR 
preparers. The pertinent evidence reveals the specific meaning of materiality assigned by Generali actors involved in the process of IR preparation.

At Generali, materiality means strategy. All members of the IR hub claim that the strategy guides them when they determine IR materiality content, such that a strategy basis defines "what deserves to be included in the IR" (IR staff 2). Any actions needed to achieve strategic objectives thus should be included in the IR. If any projects are not directly related to the strategic objectives, they still may be important but not sufficiently material to be included in the IR.

Strategy has always been central to the document, since the first IR in 2013, such that "Since our first IR, we have assumed that materiality is equal to strategy" (IR staff 2). With the acknowledgment that it may represent a simplification, Generali has maintained this sense over time and still considers it an appropriate approach. The IR preparers thus refer to the group's corporate strategy, as established by the board of directors and publicly communicated at the Investor Day by the CEO, CFO and top management. The latest IRs $(2015,2016)$ even present the recently updated strategy for 2015-2018.

As the principal input for IR preparation, the strategy is public, with related documents available on the website. A specific section of the site refers to the Investor Day. In this sense, "we are lucky that since we began this journey we had a public strategy to communicate. In the past, it would have been more difficult because the group strategy used not to be public" (IR staff 1). As noted by the head of the Group IR framework, the current group strategy mentions the importance of customer relationships, so relationships with customers necessarily will be included in the IR. Another example is the importance of the brand, something new in 2016 with respect to previous strategies. The company thus has been working on how to include this information in its next IR, possibly in a new, specific section that did not appear in previous years.

In the IR preparers' view, materiality also relates strictly to the principle of conciseness, such that the IR is a document that is "concise by nature; for this reason only information that is really important should be included" (IR staff 2). The IR preparers stress that if additional information is needed, other documents can provide it, such as the sustainability report. In accordance with such referrals to other sources of information, the company currently is "trying to strengthen and be more explicit on the connection between IR and the materiality matrix exposed in the sustainability report" (head of the Group IR framework). The plan for coming years is to signpost any issue that is reported in the IR and also present it in the sustainability report. For example, if demographic change appears in the IR and the sustainability matrix, the IR will report that demographic change appears in the sustainability materiality matrix too, and vice versa. Thus far though, the IRs have not made any explicit mention to the materiality matrix, which seemingly reflects the goal of conciseness. The sustainability report can provide a more detailed explanation of that information that is reported, concisely and with a strategic view, in the IR. Therefore, when it comes to what materiality is in the 
$I R$, the concept is inextricably linked to strategy, and the IR is conceived of as an instrument for communicating corporate strategy, as it cascades across the group.

The adoption of Generali IR took place at a critical moment for the company, marked by major changes in the top management. Both the CEO and CFO changed in 2012, and the new top management actively sponsored IR to facilitate its adoption and preparation. A fundamental change in the corporate strategy also occurred following the new CEO's appointment, and the "IR has perfectly matched with the new CEO vision" (head of the IR hub). However, even the previous top management "was curious about IR" (head of the IR hub), and the previous CFO issued an exploratory mandate to pursue a better understanding of IR. As this fundamental step shows, "IR was already in the DNA of Generali although the advent and support of both the new CFO and CFO has allowed the IR to blossom" (head of the IR hub).

The meaning assigned to the materiality principle thus has been strongly influenced by the evolving company strategy and its willingness to communicate about this change through proper channels. All the interviewees indicated that the new top management perceived a growing demand among external stakeholders, and investors in particular, to know more about Generali's strategy and value-creation process-information that was not effectively reported in traditional financial statements. According to the Group CFO and General Manager, prior to IR, the annual report failed to provide readers with any representation of what the company was doing, other than reporting numbers, whereas the "IR could make the annual report intelligible" (Group CFO and General Manager) and explain value creation in the insurance industry, which can be difficult to understand. Finally, Generali perceived the need to communicate better internally: "We need to give a clearer, more transparent picture internally to favour engagement" (Group Communication Manager).

\section{Discussion}

The IR preparation process in Generali takes the materiality principle into consideration and assigns it a specific meaning: What is material is what reveals the corporate strategy. An interpretation of materiality as a social construction helps clarify how this meaning gets constructed, as well as its role in the social world in which the IR was conceived, through the assignment of a function, a shared collective intentionality and constitutive rules (Searle, 1995, 2010).

The findings from this analysis reveal that new leadership wanted to communicate Generali's renewed business strategy (and the related mission, main values and business model) and disclose financial information that could qualify the results of this strategy. As a consequence, it assigned a pertinent function to the IR and aligned the definition of materiality with its business strategy (Stubbs and Higgins, 2014). Because the IR was "invested in the ability of communicating the strategy in a way that meets expectations, and the strategy itself meets expectations" (Higgins et al., 2014, p. 1108), the board's and managers' efforts were accordant with the underlying idea. 
The preparers also addressed the challenges surrounding the application of the principle (AICPA and IIRC, 2013; EY, 2013; IIRC 2015; CDP et al., 2016; IAAER et al., 2016) by making a "strong" subjective ontological choice (i.e. assign a strategy meaning to the materiality principle) that simplified the different possible solutions. Not only was the meaning of the materiality principle coherent with the IR framework, but it is simple, clear and exogenous to conventional financial reporting. The ontological choice thus cannot be taken for granted, even if supportive advice about materiality may be available from qualified entities (IIRC, 2013; IAAER et al., 2016). The choice entails addressing a theme that many companies avoid sharing with their stakeholders, but doing so enables them to meet the needs of actors seeking the deep insights available from more entityspecific, communicative and de-cluttered corporate reporting (Rowbottom and Locke, 2015). In this sense, the significance assigned to the materiality principle is even stronger, in terms of the role of IR within Generali's corporate reporting: It is not to provide a simpler or more attractive form (i.e. more concise, freer from "narrow" schemes) to the non-financial subjects that also appear in social, environmental or sustainability reporting, nor was it to exclude reporting on issues on which the company performs poorly (Stubbs and Higgins, 2014, p. 1084). Generali prepares its IR in a sector (insurance) that already provides specific information in financial reports (and other corporate documents) but that is less familiar to many investors who usually work with industrial or commercial sectors. Even if investors recognize that the sector offers good opportunities, they may be uncomfortable because they lack a deep comprehension of where an insurance company is heading, how to interpret its results and how to assess its strategy in terms of those results.

In response, Generali's IR preparers apply the materiality principle intentionally, to explain what is relevant and fill the gap, thereby helping people less familiar with the industry a clear sense of its strategy. That is, the IR provides fuller consciousness to people who already have invested in the company or are considering doing so. Debt owners may be interested in the strategy just to check the financial sustainability of their debtor (they rarely earn returns solely on the basis of different strategies), but the preparers want to link the information usually provided in financial reports with the company's strategy.

Accordingly, the company developed a constitutive rule (Searle, 2010) that appears unusual in the insurance sector: It replaced the traditional management commentary at the start of financial reports with its IR. Therefore, Generali is convinced that even the conventional significance of reporting might change, through the meaning of the materiality principle embedded in the IR. The preparers do not just respond to but also create the very possibility of such purpose (Searle, 1995). As an epistemological choice, they also trust that by giving materiality a strategy meaning, they can satisfy the knowledge demands of investors and stakeholders in the new social world, so IR is complementary to traditional financial reports. That is, the IR can satisfy the important need expressed by the board to reveal the corporate strategy, but it also can transform traditional forms of reporting by connecting financial information with strategy. In contrast with traditional forms of 
reporting (Brennan and Grey, 2005), the meaning of the materiality principle goes beyond the "narrow myopic lens" (Edgley, 2011, p. 23) that characterises many reporting choices.

The other constitutive rule for implementing the materiality principle consists of selecting what to insert into the IR, not deciding which immaterial information to exclude, as is typical of financial reporting (Berstein, 1967; Brennan and Gray, 2005). The materiality determination process attempts to establish content that might have an influence on the firm's capability to create value in the short, medium and long terms (IIRC, 2015), identified by Generali as its strategy. This aspect differs from establishing thresholds to limit the magnitude of misstatements. By giving a strategy meaning to the materiality principle, the process is carried out by actors who believe in and embrace a shared intentionality (Searle, 1995, 2010).

The assignment of a function to the materiality principle is relevant for the ontological choice but also for its epistemological consequences. It is coherently and continuously realized through the interactions of the board (i.e., president and CEO), managers and users of the IR. For the preparers, the IR tool was a valuable way to assign relevance to issues they wanted to share with investors (more than other stakeholders) and internally. Preparers and users (who and to whom; Eccles and Krutz, 2014) are constitutively linked in this new social space. In turn, IR construction was never conceived as a top-down process but rather as an interactive relationship among the board and managers to foster relevant choices and create rules about which issues to present and disclose in the IR. This collective intentionality (Searle, 1995) offers empirical evidence of the epistemological process involved in building a new form of social construction. In this world, everyone cooperates to improve the information available (i.e. collective intentionality in planning and acting; Searle, 2010, p. 43), which is a need that must be satisfied together. The chosen continuous flow of information passes through different interactions, starting with connections between investors and the board, the investor relator and the CFO. These connections force upper management to explicate the most relevant issues, which will be presented during the Investor Day. They also involve investors in this process and obtain feedback during the event. Other connections established at the top management levels support the definition of the relevant issues, such as selecting relevant strategic matters (and results) to build social consensus among actual and potential investors. The strategy, and the value-creation story in general, featured in the IR thus embeds elements that already had been shared, at least partially, with IR addressees. Yet the IR gives investors an added benefit, in that they can assess the information presented during the Investor Day in a document that includes further details of the strategy, the business model and their connections with the company's results and specific KPIs. The material contents selected during the IR preparation and reported in the IR final document enable shareholders to check the accuracy of the previously told story, in which they already are embedded.

Internal interactions also deserve attention, as a form of collective intentionality. The materiality determination relies on interactions among all the offices involved in IR preparation. The IR hub 
continuously considers relevant topics, to giving evidence in support of the story the board wants to write, by soliciting input from various offices and departments throughout the organization. The staff involved in these interactions help build a deeper internal sense of belonging, through the meaning assigned and shared about the materiality principle, so that "it is not just a cooperative behaviour, but they share intentional states such as beliefs, desires, and intentions" (Searle, 1995, p. 23). Some of these staffers are responsible for supplying information to the IR team, on actually or potentially material matters, which then defines the content of the IR. In this sense, IR preparation requires a complex, extended dialog between the IR team and these different offices to refine and select the information provided, as well as to ensure it is logically in tune with the ideas that the company wants to share with its audience. This interaction integrates these offices into the IR preparation process, so this supplying activity (of material information) helps link diverse staff across different departments, promising deeper social binding.

Other staffers, while less involved in the IR preparation process, are addressees of the IR. The IR content expands their knowledge of the corporate strategy. For many workers, their daily work does not give them a means to consider the big questions or overall goals of their company. But the $\mathrm{IR}$ and its material issues can help them identify what makes their own work essential to achieving the strategy and value-creation story. As staff members become familiar with the IR content, it may change the way they perceive their roles in the organization; eventually, their actions should converge toward the goals declared in the IR, assuming they regard these goals as relevant for the overall organization. Any time a theme is identified as relevant during the IR preparation process, the choice affects the role that employees and managers who read the report take in the valuecreation story. Because this choice can increase their sense of belonging and their comprehension of their role in implementing the company strategy, these material subjects build and reinforce the links between employees and their organizations, even if they are not directly involved in the materiality determination process.

As highlighted by the professional literature, the findings confirm the great subjectivity in implementing the materiality principle within the IR context. However, despite the warnings coming from the academic research, materiality is not used to rhetorically report on sustainability achievements (Unerman and Zappettini, 2014), nor to exclude negative information by focusing on fewer "more strategic" issues (Stubb and Higgins, 2014).

\section{Conclusions}

Differently from both the financial and the sustainability reporting contexts, implementing materiality within the IR one is not about deciding what information to exclude, nor about identifying single impacts on corporate sustainability: Materiality is strictly connected to the very function 
preparers assign to the IR. The findings reveal that the IR is not just an instrument to simplify or shape the information provided to recipients (Higgins et al., 2014) or to provide a "gain" for some audience the preparers have in mind (Rowbottom and Locke, 2015). If materiality takes a strategy meaning and helps build a social construct, because that is the function assigned to it (Searle, 1995, 2010), then the relevant choices cannot to be conceived solely as tools to manage impressions. The focal strategy cannot be short lived, as greenwashing efforts tend to be, because the company would lose credibility if it disclosed strategies it failed to achieve. Because subsequent IR releases can be compared easily, this credibility issue would be evident, especially when the material matters related to the strategy include financial aspects, results of prior strategies or KPIs measuring the impacts of management policies. This choice satisfies the need for criteria related to the materiality principle (Bernstein, 1967, p. 89), in line with the IIRC requirements (IIRC, 2013, 2015).

The choice to explain and share strategy through the IR also offers new perspectives on the narrative aspects of financial reporting, such that it qualifies them through a new constitutive rule. The IR can replace the management commentary, by combining it with company KPIs and by presenting the business model together with the strategy. These features expand the usefulness of the IR, to the point that it may become the primary document given to investors, particularly if traditional financial reports are difficult to read and comprehend. This situation requires a careful choice of the real material themes to include in the IR, so that such a substitution will be accepted and even eventually requested by audiences who usually receive traditional reports. For Generali, this solution was widely favoured, due to the complexity of financial reports in the insurance industry, but IRs could have similarly significant roles in other sectors, as long as it is possible to assign meaning to the materiality principle and involve addressees in the determination process. This key implication of the current study should inform considerations by other preparers, who should seek to link their strategy with traditional financial information, through an IR embedded in their financial reports. This option grants them a means to face the challenges the materiality principle offers, but even more, it is a way to bring all the relevant participants into a simple social construction. This purpose is not just a consequence of an existing ontological choice; it exerts an effect on epistemological aspects of this subjective choice, because the preparers provide full coherence about the materiality determination process, using it to embed different actors. This coherence is another fruitful outcome for preparers and academics that, even if it originates in methodological issues, has relevant practical implications.

The Generali materiality determination process suffers the criticisms raised in previous studies that suggest IR preparers focus on fewer, more strategic issues rather than lots of issues, such as those covered by the GRI (Stubbs and Higgins, 2014, p. 1082). In the case, the situation is clearly different: The Generali IR did not result from a tradition of sustainability reporting or from the need to provide information that readers could find elsewhere. Generali does not prepare its IR just to match a pre-defined format or prevent visibility on some issues by offering a more concise report or 
distracting readers from inconvenient themes (Unerman and Zappettini, 2014). Instead, the IR meets a need, by combining a willingness to declare the company's strategy with the effort to select relevant information to disclose. Thus, materiality is fundamental to the preparation of this IR report. Yet for Generali, this challenge was relatively easy to solve, because the main purposes to address were clear: communicate the strategy inside and outside the company. The moderate changes to the IR of Generali over time (since the first appearance in 2013) represent a significant strategic evolution in this short period.

This research is not free of limitations though. The meaning assigned to the materiality principle was strongly influenced by changes in the board of directors and the subsequent willingness to demonstrate this change. It would be interesting to test the continuity of this solution, over the medium or long term. Moreover, the technicalities typical of traditional reporting in the insurance industry forced the IR team to avoid a materiality that might have enabled a broader disclosure of financial results and a comparison with competitors, which could be relevant to investors. It would be interesting to compare how the definition process might inform the choice of the materiality meaning in different sectors. Finally, the analysis is based on a single case, so it is not possible to determine if the meaning assigned to the materiality principle really satisfies the need to recognize the different strategies of various companies or if the effect of this choice leads to boilerplate information in the IR. Such an analysis could be possible by considering more materiality definition processes by multiple companies within the same industry.

\section{References}

AAA (American Accounting Association) (1957). "Accounting \& reporting standards for corporate financial statements \& preceding statements \& supplements", American Accounting Association, Sarasota.

AASB (Austrialian Accounting Standard Board) (2010), "Materiality", available at: http://www.aasb.gov.au /admin/file/content105/c9/AASB1031 07-04 COMPdec09 01-11.pdf (accessed 10 June 2017).

AccountAbility (2008), AA1000 AccountAbility principles standard 2008, available at: https://www. accountability.org/wp-content/uploads/2016/10/AA1000APS english.pdf $+\& c d=2 \& h l=i t \& c t=c l n k \& g l=i t$ (accessed 10 June 2017).

AICPA (America Institute of Certified Public Accountants) and IIRC (International Integrated Reporting Council) (2013), "Materiality. Background paper for <IR>", available at: http://integratedreporting. org/wpcontent/uploads/2013/03/IR-Background-Paper-Materiality.pdf (accessed 10 June 2017).

Atkins, J. F., Solomon, A., Norton, S. and Joseph, N.L. (2015), "The emergence of integrated private reporting", Meditari Accountancy Research, Vol. 23 No. 1, pp. 28-61.

Barker, R. and Schulte, S. (2017), "Representing the market perspective: Fair value measurement for nonfinancial assets", Accounting, Organizations and Society, Vol. 56, pp. 55-67.

Bernstein, L.A. (1967), "The concept of materiality" The Accounting Review, Vol. 42 No. 1, pp. 86-95.

Beattie, V. (2014), "Accounting narratives and the narrative turn in accounting research: Issues, theory, methodology, methods and a research framework", The British Accounting Review, Vol. 46 No. 2, pp. 111-134.

Boele, R., and Kemp, D. (2005), "Social auditors: illegitimate offspring of the audit family? Finding legitimacy through a hybrid approach", The Journal of Corporate Citizenship, Vol. 17, pp. 109-119.

Brennan N. and Gray S. (2005), "The impact of materiality: accounting's best kept secret", Asian Academy of Management Journal of Accounting and Finance, Vol. 1, pp. 1-31.

Carpenter, B.W., Dirsmith, M.W. and Gupta, P.P. (1994), "Materiality judgments and audit firm culture: Socialbehavioral and political perspectives", Accounting, Organizations and Society, Vol. 19 No. 4-5, pp. 355380.

CDP, CDSB, GRI, IFRS, IIRC, ISO, SASB (2016), "Statement of Common Principles of Materiality of the Corporate Reporting Dialogue", available at: http://corporatereportingdialogue.com/wp- 
content/uploads/2016/03/ Statement-of-Common-Principles-of-Materiality1.pdf (accessed 10 June 2017)

de Villiers, C., Rinaldi, L. and Unerman, J. (2014), "Integrated Reporting: Insights, gaps and an agenda for future research", Accounting, Auditing \& Accountability Journal, Vol. 27 No. 7, pp. 1042-1067.

de Villiers, C., Rinaldi, L. and Unerman, J. (2015), Special issue on Case study insights from the implementation of Integrated Reporting, http://www.emeraldgrouppublishing.com/authors/writing/calls. htm?id=6194.

Dohr J.L. (1950), "Materiality - What Does It Mean in Accounting?", Journal of Accountancy, Vol. 122 No. 1, pp. 54-56.

Deloitte (2010), "Conceptual Framework for Financial Reporting 2010", available at: https://www.iasplus.com/en/standards/other/framework (accessed 10 June 2017).

Eccles, R.G. and Krzus, M.P. (2014). The integrated reporting movement: meaning, momentum, motives, and materiality. John Wiley \& Sons, New York, NY.

Eccles, R.G., Krzus, M.P., Rogers, J., and Serafeim, G. (2012), "The Need for Sector-Specific Materiality and Sustainability Reporting Standards", Journal of Applied Corporate Finance, Vol. 24 No. 2, pp. 65-71.

Edgley, C. (2011), A Genealogy of Accounting Materiality, Critical Perspectives on Accounting Conference, Clearwater, 10-12 July, 2011, available at http://elsevier.conferenceservices.net/resources/247/2182/pdf/cpac2011 0091 paper.pdf (accessed 10 June 2017).

Eccles, R.G., and Youmans, T. (2016), Materiality in Corporate Governance: The Statement of Significant Audiences and Materiality, Journal of Applied Corporate Finance, Vol. 28 No. 2, pp. 39-46.

Edgley, C. (2014), "A genealogy of accounting materiality", Critical Perspectives on Accounting, Vol. 25 No. 3 , pp. 255-271.

ESMA (European Securities and Markets Authority) (2011), Consultation Paper - Considerations of materiality in financial reporting, available at: https://www.esma.europa.eu/file/10148/download?token materiality 20120227\%20(2).pdf (accessed 10 June 2017).

EY (2013), The concept of "materiality" in Integrated Reporting, available at: http://www.ey.com/Publication/vwLUAssets/The concept of materiality in Integrated Reporting July 2013/\$FILE/EY-the-concept-of-materiality-in-integrated-reporting-july-2013.pdf (accessed 10 June 2017).

Fasan, M., and Mio, C. (2016), "Fostering stakeholder engagement: The role of materiality disclosure in Integrated Reporting", Business Strategy and the Environment, Vol. 26 No. 3, pp. 88-305.

GRI (Global Reporting Initiative) (2013), "Materiality", available at: https://g4.globalreporting.org/how-youshould-report/reporting-principles/principles-for-defining-report-content/materiality/Pages/default.aspx (accessed 10 June 2017).

Guthrie, J. and Parker, L.D. (1990), "Corporate social disclosure practice: a comparative international analysis", Advances in public interest accounting, Vol. 3, pp. 159-175.

Hicks, E.L. (1964), "Materiality", Journal of Accounting Research, Vol. 2 No. 2, pp. 158-171.

Higgins, C., Stubbs, W. and Love, T. (2014), "Walking the talk(s): Organisational narratives of integrated reporting", Accounting, Auditing \& Accountability Journal, Vol. 27 No. 7, pp. 1090-1119.

Hines, R.D. (1988), "Financial accounting: in communicating reality, we construct reality", Accounting, organizations and society, Vol. 13 No. 3, pp. 251-261.

Holmes, W. (1972), "Materiality-Through the looking glass", Journal of Accountancy, Vol. 133 No. 2, pp. 4449.

Humphrey, C., O'Dwyer, B. and Unerman, J. (2017). "Re-theorizing the configuration of organizational fields: the IIRC and the pursuit of 'Enlightened' corporate reporting", Accounting and Business Research, Vol. 47 No. 1 , pp. 30-63.

IAAER, IIRC and ACCA (2016), "Factors affecting preparers' and auditors' judgements about materiality and conciseness in Integrated Reporting", available at: http://www.accaglobal.com/content/dam IACCA Global/Technical/integrate/pi-materiality-conciseness-ir-.pdf (accessed 10 June 2017).

IIRC (International Integrated Reporting Council) (2013), "International Integrated Reporting Framework", available at: http://integratedreporting.org/wp-content/uploads/2015/03/13-12-08-THEINTERNATIONAL-IR-FRAMEWORK-2-1.pdf (accessed 10 June 2017).

10 JunelIRC (International Integrated Reporting Council) (2015). "Materiality in <lR>. Guidance for the preparation of integrated reports", available at: http://integratedreporting.org/wpcontent/uploads/2015/11/1315 MaterialityinIR Doc 4a Interactive.pdf (accessed 10 June 2017).

Kallinikos, J. (2012). Form, function, and matter: Crossing the border of materiality. In Leonardi, P.M., Nardi, B.A. and Kallinikos J. (eds.), Materiality and organizing: Social interaction in a technological world, Oxford University Press, Oxford, pp. 67-87. 
KPMG (2014), "The essentials of materiality assessment", available at: https://assets.kpmg.com/content/dam/kpmg/pdf/2014/10/materiality-assessment.pdf $\quad$ (accessed 10 June 2017).

Lee, T.A. (2006), "The FASB and accounting for economic reality", Accounting and the Public Interest, Vol. 6 No. 1, pp. 1-21.

Lee, T.A. (2009), "The ontology and epistemology of social reality in accounting according to Mattessich", Accounting and the Public Interest, Vol. 9 No. 1, pp. 65-72.

Lydenberg, S. (2012), "On materiality and sustainability: the value of disclosure in the capital markets", Initiative for Responsible Investment Hauser Center for Nonprofit Organizations at Harvard University September 2012, available at: http://www.sasb.org/wp-content/uploads/2012/10/On-Materiality-andSustainability.pdf (accessed 10 June 2017).

Mattessich, R.V. (2009), "FASB and Social Reality-An Alternate Realist View", Accounting and the Public Interest, Vol. 9 No. 1, pp. 39-64.

Melloni, G., Stacchezzini, R., and Lai, A. (2016), The tone of business model disclosure: an impression management analysis of the integrated reports, Journal of Management \& Governance, Vol. 20, No. 2, pp. 295-320.

Messier W.F. Jr, Martinov-Bennie N. and Eilifsen A. (2005), "A review and integration of empirical research on materiality: two decades later", Auditing A Journal of Practice and Theory, Vol. 24 No. 2, pp.153-204.

Mio, C. (2013). "Materiality and assurance: building the link", in Busco, C., Frigo, M.L., Quattrone, P., and Riccaboni, A. (Eds.), Integrated reporting. Concepts and Cases that Redefine Corporate, Springer, New York, NY, pp. 79-94.

Mio, C. and Fasan M. (2013) "Materiality from Financial Towards Non-Financial Reporting", Department of Management, Università Ca' Foscari Venezia Working Paper No. 19/2013, available at: https://papers.ssrn.com/sol3/papers.cfm?abstract id=2340192 (accessed 10 June 2017).

Morgan, G. (1988), "Accounting as reality construction: towards a new epistemology for accounting practice", Accounting, Organizations and Society, Vol. 13 No. 5, pp. 477-485.

Mouck, T. (2004), "Institutional reality, financial reporting and the rules of the game", Accounting, Organizations and Society, Vol. 29, pp. 524-541.

PwC (2015), "Implementing Integrated Reporting”, available at: https://www.pwc.com/gx/en/auditservices/publications/assets/pwc-ir-practical-guide.pdf (accessed 10 June 2017).

Reininga, W. (1968), "The Unknown Materiality Concept”, Journal of Accountancy, Vol. 125, 30-35.

Rowbottom, N. and Locke, J. (2016), "The emergence of <IR>”, Accounting and business research, Vol. 46 No. 1, pp. 83-115.

SASB (Sustainability Accounting Standards Board (2016), "Implementation Guide for companies", available at: https://library.sasb.org/implementation-guide/ (accessed 10 June 2017).

Searle, J.R. (1995). The construction of social reality. Simon \& Schuster, New York, NY.

Searle, J.R. (2010). Making the social world: The structure of human civilization. Oxford University Press, Oxford.

Stacchezzini, R., Melloni, G., and Lai, A. (2016). Sustainability management and reporting: the role of integrated reporting for communicating corporate sustainability management, Journal of Cleaner Production, Vol. 136, pp. 102-110.

Strauss, A., and Corbin, J. (1990), Basics of qualitative research, Sage, Newbury Park, CA.

Stubbs, W. and Higgins, C. (2014), "Integrated Reporting and internal mechanisms of change", Accounting, Auditing \& Accountability Journal, Vol. 27 No. 7, pp. 1068-1089.

Tuttle, B., Coller, M. and Plumlee, R.D. (2002), "The effect of misstatements on decisions of financial statement users: An experimental investigation of auditor materiality thresholds", Auditing: A Journal of Practice \& Theory, Vol. 21 No. 1, pp. 11-27.

Unerman, J. and Zappettini, F. (2014), "Incorporating materiality considerations into analyses of absence from sustainability reporting", Social and Environmental Accountability Journal, Vol. 34 No. 3, pp. 172-186. 